\title{
Marked Heterogeneity in Growth Characteristics of Myoblast Clonal Cultures and Myoblast Mixed Cultures Obtained from the Same Individual
}

\author{
Andrea B. Maier Ron Cohen Joke Blom Diana van Heemst \\ Rudi G.J. Westendorp \\ Department of Gerontology and Geriatrics, Leiden University Medical Centre, Leiden, The Netherlands
}

\section{Key Words}

Sarcopenia $\cdot$ Satellite cells $\cdot$ Myoblasts $\cdot$ Proliferative capacity $\cdot$ Oxidative stress $\cdot$ Clone $\cdot$ Mass culture $\cdot$ Carnosine

\begin{abstract}
Background: Sarcopenia is defined as an age-related decrease in skeletal muscle mass and function while adjacent satellite cells are unable to compensate for this loss. However, myoblast cultures can be established even in the presence of sarcopenia. Objective: It is yet unknown whether satellite cells from failing muscle in older age are equally affected, as human satellite cells have been assessed using myoblast mixed cultures and not by using myoblast clonal cultures. We questioned to what extent myoblast mixed cultures reflect the in vivo characteristics of single satellite cells from adult skeletal muscle. Methods: We established a myoblast mixed culture and three myoblast clonal cultures out of the same muscle biopsy and cultured these cells for 100 days. Replicative capacity and oxidative stress resistance were compared. Results: We found marked heterogeneity between the myoblast clonal cultures that all had a significantly lower replicative capacity when compared to the mixed culture. Replicative capacity of the clonal cultures
\end{abstract}

was inversely related to the $\beta$-galactosidase activity after exposure to oxidative stress. Addition of L-carnosine enhanced the remaining replicative capacity in all cultures with a concomitant marginal decrease in $\beta$-galactosidase activity. Conclusions: It is concluded that myoblast mixed cultures in vitro do not reflect the marked heterogeneity between single isolated satellite cells. The consequences of the heterogeneity on muscle performance remain to be established.

Copyright $\odot 2011$ S. Karger AG, Basel

\section{Introduction}

Skeletal muscle is highly plastic and responds to various stresses such as exercise and injury. Lifelong muscle function relies on the maintenance and regeneration of myofibers through activation of quiescent muscle precursor cells that after proliferation fuse to differentiated myofibers [1]. These quiescent muscle precursor cells, also called satellite cells, are located between the plasma membrane and the surrounding basal lamina of the myofibers [2]. Exhaustion of the pool of satellite cells impairs muscle regeneration, as in certain diseases such as Duchenne muscular dystrophy [3].

\section{KARGER}

Fax +4161306 1234 E-Mail karger@karger.ch www.karger.com

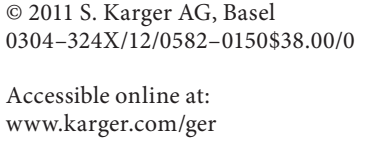

Andrea B. Maier, MD, PhD

Department of Gerontology and Geriatrics

Leiden University Medical Centre, PO Box 9600

NL-2300 RC Leiden (The Netherlands)

Tel. +31 71526 6640, E-Mail a.b.maier@lumc.nl 
Sarcopenia is defined as an age-related loss of muscle mass, strength and function and may result in a loss of the muscle mass of about $30-50 \%$ by the age of 80 years [4]. This loss is generally thought to be caused by an exhaustion of the number of, and a diminished replicative capacity of satellite cells, consequent on the regeneration of muscle and accumulation of damage from reactive oxygen species (ROS) throughout lifetime [5, 6]. In line, the fraction of satellite cells within human muscle is inversely related to the age of the donor [7-10], but others failed to find such a correlation during adulthood $[11,12]$. Replicative capacity of isolated satellite cells in vitro show a rapid decrease during childhood and adolescence but from adulthood onwards replicative capacity decreases only slightly $[8,13]$. Remarkably, however, at an older age when clinical signs of sarcopenia are clearly present, satellite cells can still be cultured in myoblast mixed cultures from muscle biopsies [8].

It is yet unknown whether satellite cells from failing muscle in older age are equally affected, or some satellite cells are affected more than others. Myofibers are of considerable length and result from a proportional number of fused myoblasts. Each fiber thus possesses many nuclei. As satellite cells have a bearing on only a distinct fragment of the myofiber and a limited number of nuclei [14], replicative failure of individual satellite cells may have major consequences on muscle function. We questioned to what extent myoblast mixed cultures reflect the in vivo characteristics of single satellite cells from adult skeletal muscle. To date, differences in proliferative capacity [15-18], differentiation $[16,19]$ and fusogenic capacity [17] of individual satellite cells have only been performed in animal models. Therefore, we compared the replicative capacity and oxidative stress resistance of myoblast clonal cultures with those of a myoblast mixed culture, which were established out of the same biopsy obtained from a middle-aged man.

\section{Materials and Methods}

\section{Muscle Sample and Cultures}

A 464-mg muscle biopsy from the musculus vastus lateralis was obtained from a 58-year-old male during elective hip replacement operation. The biopsy was washed with solution-A $[10 \mathrm{mM}$ glucose, $130 \mathrm{mM} \mathrm{NaCl}, 3 \mathrm{mM} \mathrm{KCl}, 1 \mathrm{mM} \mathrm{Na} \mathrm{HPO}_{4} 2 \mathrm{H}_{2} \mathrm{O}, 40 \mathrm{~g} / \mathrm{ml}$ $\mathrm{NaOH}$ (reagents were obtained from Merck, Schiphol, The Netherlands), $30 \mathrm{~mm}$ Hepes, $3.3 \mathrm{~nm}$ Red Phenol (Sigma, Zwijndrecht, The Netherlands), $\mathrm{H}_{2} \mathrm{O}$ ] and connective tissue was removed. The muscle was minced and digested in a trypsin-EDTA solution (solution-A, $0.005 \%$ trypsin, 0.02\% EDTA; Gibco, Breda, The Netherlands) during $1 \mathrm{~h}$ at $37^{\circ} \mathrm{C}$. Thereafter, trypsin was blocked us- ing $10 \%$ fetal calf serum (Lot 40G4932F; Gibco). Myoblasts were washed and collected in growth medium (GM) consisting of Ham's F-10 (Gibco), $0.50 \mathrm{mg} / \mathrm{ml}$ bovine serum albumin, $0.5 \mathrm{mg} /$ $\mathrm{ml}$ fetuin, $0.18 \mathrm{mg} / \mathrm{ml}$ insulin (all Sigma), $1 \mathrm{~mm}$ creatine (Fluka, Zwijndrecht, The Netherlands), $0.39 \mu \mathrm{g} / \mathrm{ml}$ dexamethasone, 100 $\mu \mathrm{g} / \mathrm{ml}$ pyruvate, $50 \mu \mathrm{g} / \mathrm{ml}$ uridine (all Sigma), $5 \mu \mathrm{g} / \mathrm{ml}$ gentamicin (Gibco), $10 \mathrm{ng} / \mathrm{ml}$ epidermal growth factor (Collaborative Research Inc., Waltham, Mass., USA) and 15\% fetal calf serum. 30,000 cells were obtained out of the biopsy $\left(64 \times 10^{3}\right.$ cells/g tissue).

8,000 cells of the established cell suspension were cultured as mixed culture in a 6-well plate. First subcultivation using a split ration of 1:4 was carried out when cells covered the entire bottom of the well plate with a confluent monolayer of myoblasts.

Myoblast clonal cultures were established out of the cell suspension by manual cloning using a micropipette und a microscope in two 96-well plates, each well containing $0.1 \mathrm{ml} \mathrm{GM}$. The three clones with the highest growth speed and juvenile morphologic phenotype were selected for further culturing and testing. Both, the mixed culture and the three clones were frozen at early passage and simultaneously cultured as secondary cultures in GM for 100 days.

Cultures were subcultured under standardized conditions using a trypsin (0.05\%) EDTA solution when $95-100 \%$ cell confluence was reached using a spit ratio of 1:4. The cumulative PD level was calculated by tracking the increase in cell number in sequential passages and therefore the sum of all previous PDs. All three myoblast clonal cultures reached the onset of senescence which was defined as failure of the culture to reach confluence within 3 weeks.

Myogenic origin of all culture was tested by differentiation of the cultures and desmin staining (Dako, Enschede, The Netherlands). All cultures proved to form myotubes and $<95 \%$ of cells were desmin positive.

\section{Oxidative Stress and $\beta$-Galactosidase Staining}

To assess senescence-associated $\beta$-galactosidase ( $\beta$-Gal) activity, myoblasts were seeded in Permanox chamber slides (Nunc, VWR, Amsterdam, The Netherlands) and grown up to $40-50 \%$ confluence. Hereafter, cultures were exposed to hydrogen peroxide $\left(\mathrm{H}_{2} \mathrm{O}_{2}\right.$; Merck) using concentrations of 1 and $5 \mathrm{mM}$ for $30 \mathrm{~min}$. After exposure, cells were washed with GM. After 3 days, cultures were fixed using formalin (3.7\%; Merck) and stained for $\beta-\mathrm{Gal}$ activity, which was measured using the cytochemical assay described by Dimri et al. [20]. In brief, adhered myoblasts were washed twice in phosphate-buffered saline (PBS), fixed with $3 \%$ formaldehyde in PBS for $3 \mathrm{~min}$, washed twice in PBS, and then stained for $18 \mathrm{~h}$ at $37^{\circ} \mathrm{C}$ with fresh $\beta$-Gal staining solution. The solution contained $1 \mathrm{mg} / \mathrm{ml} 5$-bromo-4-chloro-3-indolyl- $\beta$-Dgalactoside (X-Gal) in dimethylsulfoxide (20 mg X-Gal/ml stock), $40 \mathrm{~mm}$ citric acid/sodium phosphate, $5 \mathrm{~mm}$ potassium ferrocyanide, $5 \mathrm{~mm}$ potassium ferricyanide, $150 \mathrm{~mm} \mathrm{NaCl}, 2 \mathrm{~mm} \mathrm{MgCl}$, $\mathrm{pH}$ 6.0. Formaldehyde was purchased from Merck and all other reagents were obtained from Sigma. After staining, cells were washed twice with PBS. Cells were counterstained with Mayer's hematoxylin staining solution (Sigma) for $5 \mathrm{~min}$ and washed twice in PBS. Only myoblast cultures at subconfluence (maximal $75 \%$ confluence) were analyzed. Cells were viewed by phase contrast on a Leica microscope (Leica Microsystems, Rijswijk, The Netherlands) and photographed at a $100 \times$ magnification by a 


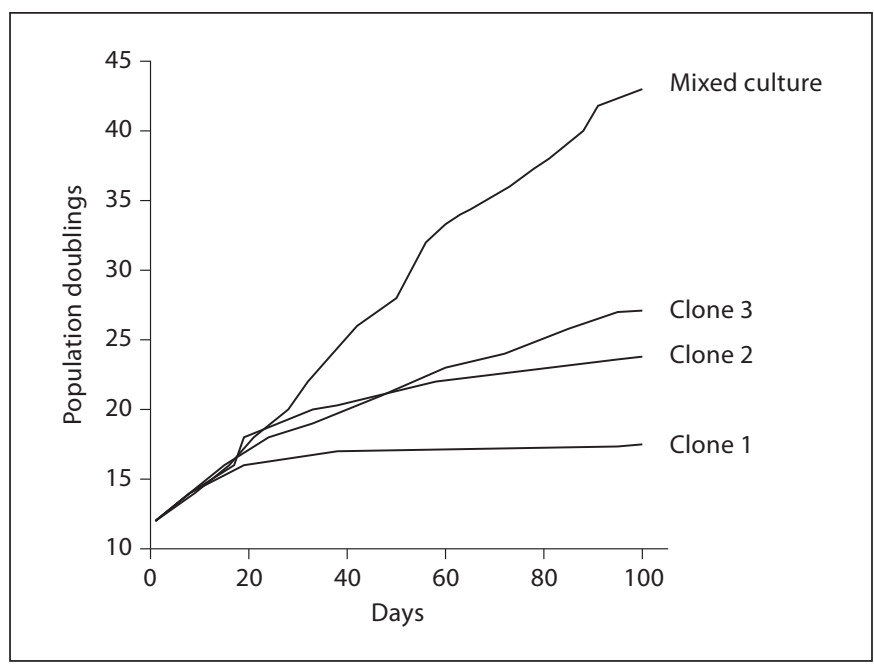

Fig. 1. Heterogeneity between growth kinetics of three myoblast clonal cultures and a mixed myoblast cell culture, all obtained from one muscle biopsy.

digital color camera. Experiments were conducted in duplicate and for each experiment at least 500 randomly selected cells were counted. The number of positive, blue cells was divided by the total number of counted cells resulting in the percentage of $\beta$ Gal-positive cells. Results from both experiments were averaged.

\section{L-Carnosine Supplementation}

At day 30 after establishment of the cultures, these were split up in cultures fed with regular GM and GM supplemented with L-carnosine (20 mM, $\geq 90.0 \%$ pure; BioChemika, Sigma). Cultures were refreshed twice a week with both media up to 100 days.

The myoblast mixed culture was exposed to oxidative stress after supplementation with L-carnosine for 14 days. $\beta$-Gal activity was measured 3 days after exposure.

\section{Statistical Analysis}

The differences between mixed cultures and clonal cultures in $\beta$-Gal positivity after induction of stress were tested by using the t test comparing means of experiments conducted in duplicate.

\section{Results}

After initiation of the cultures, the myoblast clonal cultures and the myoblast mixed culture did not significantly differ in growth speed being 0.26 population doublings $(\mathrm{PD}) /$ day. As shown in figure 1, we found a significantly lower remaining replicative capacity of all three myoblast clonal cultures that varied between 17.5 and 27.1 PDs compared to the myoblast mixed culture undergoing 43 PDs.

To test the relation between the remaining replicative capacity and resistance to oxidative stress, two myoblast

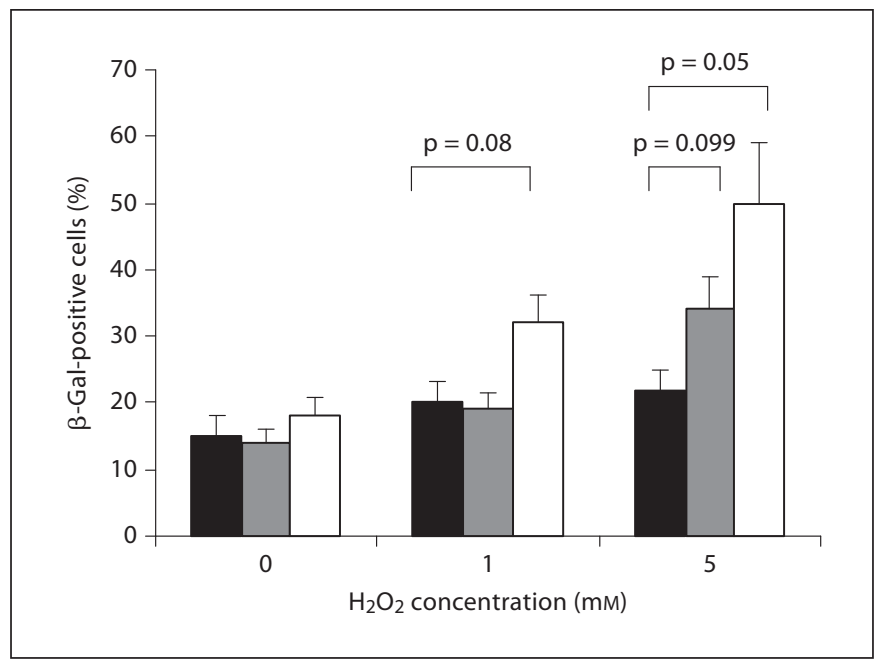

Fig. 2. $\beta$-Gal activity (mean, $\mathrm{SD}$ ) at 3 days after exposure to oxidative stress by $\mathrm{H}_{2} \mathrm{O}_{2}$. = Myoblast mixed culture; = clone 2; $\square=$ clone 1 .

clonal cultures as well as the myoblast mixed culture were exposed to $\mathrm{H}_{2} \mathrm{O}_{2}$ during the early replicative phase and tested for $\beta$-Gal activity, as marker for cellular senescence. As shown in figure 2, after exposure to $\mathrm{H}_{2} \mathrm{O}_{2}$, a higher $\beta$-Gal activity was found in the myoblast clonal cultures compared to the myoblast mixed culture, which was statistically significant for clone 1 compared to the mixed culture after expose to $5 \mathrm{mM} \mathrm{H}_{2} \mathrm{O}_{2}(\mathrm{p}=0.05)$. Within the myoblast clonal cultures, the one with the lowest remaining replicative capacity expressed the highest $\beta$-Gal capacity after exposure to oxidative stress.

To test if the replicative capacity of the cultures can be influenced by supplementation of specific nutrients, which have been suggested to influence sarcopenia, cultures were incubated with $20 \mathrm{~mm} \mathrm{~L}$-carnosine upon day 30 after establishment of the cultures. Figure 3 shows that the growth speed of all cultures as well as the maximal replicative capacity increases after continuous exposure to L-carnosine. The effect was small during the first exposure period of the myoblast mixed culture when growth speed maintained at high level. However, the $\beta$-Gal activity of the myoblast mixed culture during the early replicative phase did not significantly decrease after L-carnosine supplementation for a period of 14 days (16.9 vs. $15.0 \%)$. When the mixed culture was incubated in the presence of L-carnosine ( $20 \mathrm{mM}$ ) prior to exposure to oxidative stress by $\mathrm{H}_{2} \mathrm{O}_{2}$, a marginal decrease in $\beta$-Gal activity was observed $\left(1 \mathrm{mM} \mathrm{H}_{2} \mathrm{O}_{2}: 23.2\right.$ vs. $19.5 \%$ versus $5 \mathrm{mM} \mathrm{H}_{2} \mathrm{O}_{2}$ : 41.1 vs. $\left.35.2 \%\right)$. 


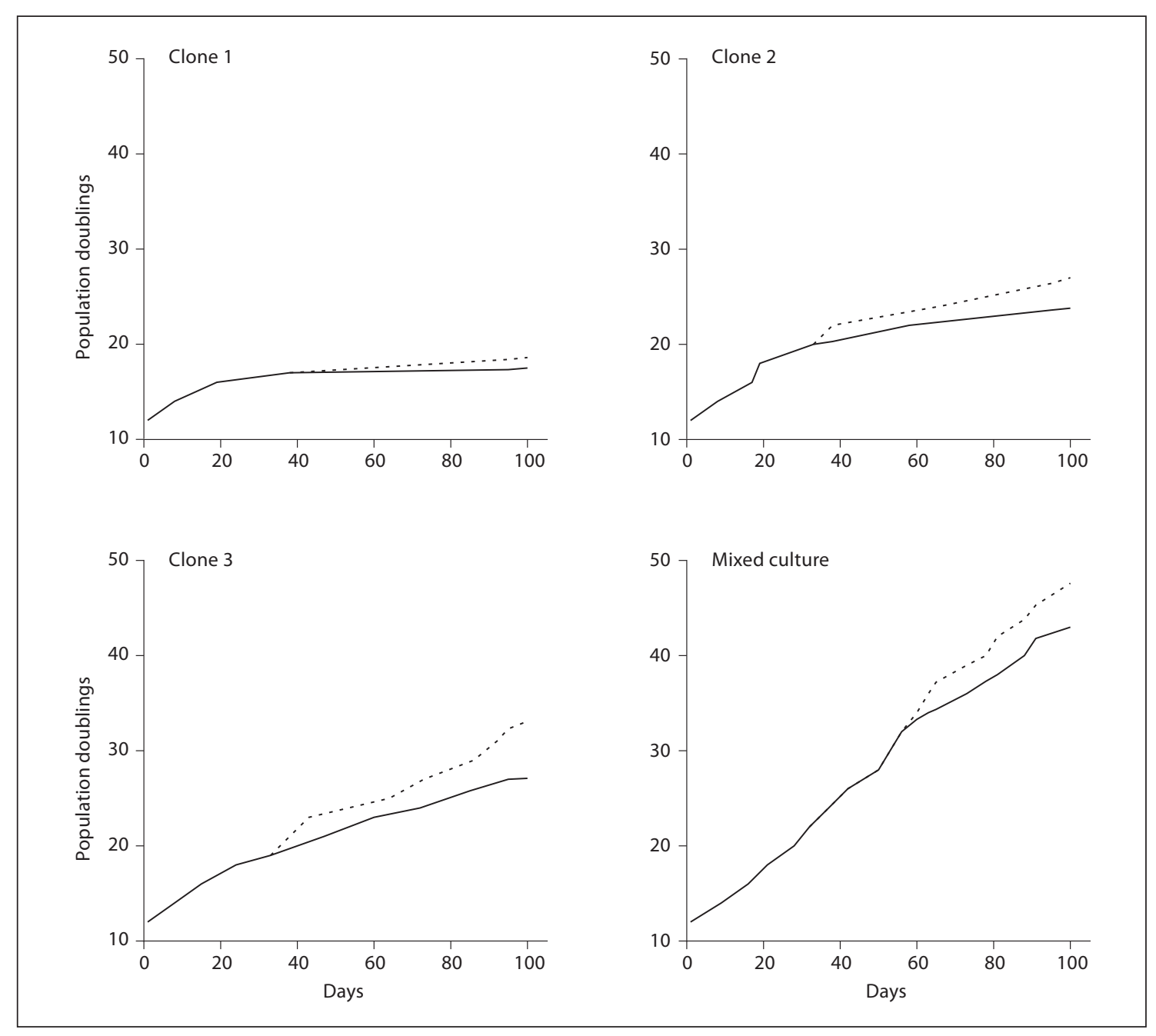

Fig. 3. Growth characteristics of myoblast cultures supplemented with $20 \mathrm{~mm}$ L-carnosine upon day 30 after initiation of the culture (- - ) compared to cultures without L-carnosine supplementation $(-)$.

\section{Discussion}

We found marked heterogeneity in replicative capacity between myoblast clonal cultures when compared to the replicative capacity of a myoblast mixed culture that all originated from the same muscle biopsy. Impaired replicative potential was mirrored by a higher expression of $\beta$-Gal activity after exposure of the various clones to oxidative stress. Addition of L-carnosine reversed the replicative capacity by a limited number of extra PDs in all cultures studied.

Myofiber regeneration during life depends on the proliferation and fusion of adjacent satellite cells. The number of PDs of myoblasts in vitro may thus represent the remaining replicative potential of satellite cells dependent on the replicative history in vivo. Despite stressors as oxidative radicals may affect all satellite cells equally, replicative histories of satellite cells may well be different as damage may occur locally and randomly. The marked heterogeneity in remaining replicative capacity between the various clones that are reported here are in line with this notion. Our results in man concur with earlier observations in turkeys showing that satellite cells are composed of a heterogeneous population that reflect their replicative capacity as measured by colony sizes [17].

Cells out of a biopsy form a mixture of clones with varying growth potential because of difference in their in 
vivo history [21]. Satellite cells with certain cellular characteristics, namely a high growth speed, which have also been associated with characteristics in differentiation $[16$, 17], and a highly remaining replicative capacity will dominate the culture during the phase of steady proliferation. Therefore, it is not surprising that the replicative capacity of the mixed culture, dominated by the clones with the highest replicative capacity and growth speed, was superior to that of the individual clones.

Oxidative damage is generally assumed to negatively influence replicative senescence, an effect that has predominantly been studied in human fibroblast cultures $[22,23]$. In rat and human skeletal muscle, a decreased antioxidative capacity is present in an age-dependent manner $[5,24]$, which suggests a clear role in the progression of sarcopenia and its significant contribution of the regenerative potential of muscle fibers [6]. Renault et al. [25] showed a dramatic decrease of viable myoblasts after treatment with $\mathrm{H}_{2} \mathrm{O}_{2}$, whereas the replicative capacity of the remaining cells, forming the mixed culture, was only slightly decreased and differentiation not affected. Our experiments focused on the heterogeneity between myoblast clones and myoblast mixed cultures. In line with the superior replicative potential of the myoblast culture, the mixed culture was far more resistant to oxidative stress as measured by the induction of $\beta-\mathrm{Gal}$ activity. As we also found expression of $\beta$-Gal activity after exposure to oxidative stress to be proportional to the remaining replicative capacity of the cultures, these findings suggest that satellite cells have accumulated different loads of oxidative damage and/or replicative history.

L-Carnosine, an endogenous cytoplasmatic dipeptide ( $\beta$-alanyl-L-histidine), is predominantly present in skel- etal muscle/neuronal cells [26] and possesses several biological functions, including $\mathrm{pH}$ buffering $[27,28]$, antioxidation [28], membrane stabilization, sensitizing the contractile apparatus to $\mathrm{Ca}^{2+}$ and potentiating $\mathrm{Ca}^{2+}$ release [29]. The production decreases in an age-dependent manner. Here, for the first time we showed that L-carnosine continuously supplemented to the culture medium, increases the growth speed as well as the replicative potential of human myoblasts, which underlines the antioxidant free radical scavenging property of L-carnosine. Extended in vitro lifespan in the presence of L-carnosine has also been reported in fibroblast cultures [30, 31] and in T-helper cells [32]. The cellular rejuvenation induced by $\mathrm{L}$-carnosine has been related to a reduction in telomere damage and shortening rate [30]. In fibroblast cultures at the end of their replicative lifespan, $\beta$-Gal activity was lower with addition of L-carnosine [30]; however, in our preliminary set of experiments, $\beta$-Gal activity in the mixed myoblast culture was only marginally reduced after exposure to oxidative stress.

It is concluded that myoblast mixed cultures in vitro do not reflect the marked heterogeneity in replicative capacity between single isolated satellite cells and may overestimate the remaining replicative capacity and with that the remaining fiber-regenerative capacity in vivo. There is a need for focus on the consequences of the heterogeneity of single satellite cells on muscle performance in aged individuals suffering from sarcopenia.

\section{Acknowledgment}

We thank Dr. P. Brawand, Department of Physiology, University Medical Center, Geneva, for providing the protocols to isolate and culture human satellite cells.

\section{References}

1 Morgan JE, Partridge TA: Muscle satellite cells. Int J Biochem Cell Biol 2003;35:11511156.

2 Mauro A, Dams WR: The structure of the sarcolemma of the frog skeletal muscle fiber. J Biophys Biochem Cytol 1961;10(suppl): 177-185.

3 Shi X, Garry DJ: Muscle stem cells in development, regeneration, and disease. Genes Dev 2006;20:1692-1708.

$\checkmark 4$ Evans W: Functional and metabolic consequences of sarcopenia. J Nutr 1997; 127(suppl):S998-S1003.
5 Hepple RT, Hagen JL, Krause DJ, Jackson CC: Aerobic power declines with aging in rat skeletal muscles perfused at matched convective $\mathrm{O}_{2}$ delivery. J Appl Physiol 2003;94: 744-751.

6 Fulle S, Di Donna S, Puglielli C, Pietrangelo T, Beccafico S, Bellomo R, Protasi F, Fanò G: Age-dependent imbalance of the antioxidative system in human satellite cells. Exp Gerontol 2005;40:189-197.

>7 Renault V, Thornell LE, Eriksson PO, ButlerBrowne G, Mouly V: Regenerative potential of human skeletal muscle during aging. Aging Cell 2002;1:132-139. $\checkmark 8$ Renault V, Piron-Hamelin G, Forestier C, DiDonna S, Decary S, Hentati F, Saillant G, Butler-Browne GS, Mouly V: Skeletal muscle regeneration and the mitotic clock. Exp Gerontol 2000;35:711-719.

-9 Sajko S, Kubínová L, Cvetko E, Kreft M, Wernig A, Erzen I: Frequency of M-cadherin-stained satellite cells declines in human muscles during aging. J Histochem Cytochem 2004;52:179-185.

10 Schmalbruch H, Hellhammer U: The number of satellite cells in normal human muscle. Anat Rec 1976;185:279-287. 
11 Hikida RS, Walsh S, Barylski N, Campos G, Hagerman FC, Staron RS: Is hypertrophy limited in elderly muscle fibers? A comparison of elderly and young strength-trained men. Basic Appl Myol 1998;8:419-427.

12 Roth SM, Martel GF, Ivey FM, Lemmer JT, Metter EJ, Hurley BF, Rogers MA: Skeletal muscle satellite cell populations in healthy young and older men and women. Anat Rec 2000;260:351-358.

13 Decary S, Mouly V, Hamida CB, Sautet A, Barbet JP, Butler-Browne GS: Replicative potential and telomere length in human skeletal muscle: implications for satellite cell-mediated gene therapy. Hum Gene Ther 1997;8: 1429-1438.

- 14 Allen DL, Roy RR, Edgerton VR: Myonuclear domains in muscle adaptation and disease. Muscle Nerve 1999;22:1350-1360.

- 15 Beauchamp JR, Morgan JE, Pagel CN, Partridge TA: Dynamics of myoblast transplantation reveal a discrete minority of precursors with stem cell-like properties as the myogenic source. J Cell Biol 1999;144:1113-1122.

-16 Rantanen J, Hurme T, Lukka R, Heino J, Kalimo $\mathrm{H}$ : Satellite cell proliferation and the expression of myogenin and desmin in regenerating skeletal muscle: evidence for two different populations of satellite cells. Lab Invest 1995;72:341-347.

- 17 Rouger K, Brault M, Daval N, Leroux I, Guigand L, Lesoeur J, Fernandez B, Cherel, Y: Muscle satellite cell heterogeneity: in vitro and in vivo evidences for populations that fuse differently. Cell Tissue Res 2004;317: 319-326.
8 Yablonka-Reuveni Z, Quinn LS, Nameroff M: Isolation and clonal analysis of satellite cells from chicken pectoralis muscle. Dev Biol 1987;119:252-259.

19 Zammit PS, Golding JP, Nagata Y, Hudon V, Partridge TA, Beauchamp JR: Muscle satellite cells adopt divergent fates: a mechanism for self-renewal? J Cell Biol 2004;166:347357.

20 Dimri GP, Lee X, Basile G, Acosta M, Scott G, Roskelley C, Medrano EE, Linskens M, Rubelj I, Pereira-Smith O, et al: A biomarker that identifies senescent human cells in culture and in aging skin in vivo. Proc Natl Acad Sci USA 1995;92:9363-9367.

21 Bayreuther K, Rodemann HP, Francz PI, Maier K: Differentiation of fibroblast stem cells. J Cell Sci Suppl 1988;10:115-130.

-22 Chen Q, Fischer A, Reagan JD, Yan LJ, Ames BN: Oxidative DNA damage and senescence of human diploid fibroblast cells. Proc Natl Acad Sci USA 1995;92:4337-4341.

23 Von Zglinicki T, Saretzki G, Döcke W, Lotze C: Mild hyperoxia shortens telomeres and inhibits proliferation of fibroblasts: a model for senescence? Exp Cell Res 1995;220:186193.

24 Fulle S, Protasi F, Di Tano G, Pietrangelo T, Beltramin A, Boncompagni S, Vecchiet L, Fanò G: The contribution of reactive oxygen species to sarcopenia and muscle ageing. Exp Gerontol 2004;39:17-24.

25 Renault V, Rolland E, Thornell LE, Mouly V, Butler-Browne G: Distribution of satellite cells in the human vastus lateralis muscle during aging. Exp Gerontol 2002;37:15131514
26 Kohen R, Yamamoto Y, Cundy KC, Ames $\mathrm{BN}$ : Antioxidant activity of carnosine, homocarnosine, and anserine present in muscle and brain. Proc Natl Acad Sci USA 1988; 85:3175-3179.

27 Harris RC, Marlin DJ, Dunnett M, Snow DH, Hultman E: Muscle buffering capacity and dipeptide content in the thoroughbred horse, greyhound dog and man. Comp Biochem Physiol A 1990;97:249-251.

28 Boldyrev AA, Koldobski A, Kurella E, Maltseva V, Stvolinski S: Natural histidine-containing dipeptide carnosine as a potent hydrophilic antioxidant with membrane stabilizing function. A biomedical aspect. Mol Chem Neuropathol 1993;19:185-192.

29 Lamont C, Miller DJ: Calcium sensitizing action of carnosine and other endogenous imidazoles in chemically skinned striated muscle. J Physiol 1992;454:421-434.

>30 Shao L, Li QH, Tan Z: L-Carnosine reduces telomere damage and shortening rate in cultured normal fibroblasts. Biochem Biophys Res Commun 2004;324:931-936.

31 McFarland GA, Holliday R: Further evidence for the rejuvenating effects of the dipeptide L-carnosine on cultured human diploid fibroblasts. Exp Gerontol 1999;34:3545.

32 Hyland P, Duggan O, Hipkiss A, Barnett C, Barnett Y: The effects of carnosine on oxidative DNA damage levels and in vitro lifespan in human peripheral blood derived CD4+ Tcell clones. Mech Ageing Dev 2000;121:203215. 